Correspondence: Philippe Bonniaud, Service de Pneumologie et Soins Intensifs Respiratoires, CHU Le Bocage, 21079 Dijon, France. E-mail: philippe.bonniaud@chu-dijon.fr

Received: Dec 102013 | Accepted after revision: March 262014 | First published online: May 22014

Conflict of interest: Disclosures can be found alongside the online version of this article at erj.ersjournals.com

\title{
References
}

1 Frankel SK, Cool CD, Lynch DA, et al. Idiopathic pleuroparenchymal fibroelastosis: description of a novel clinicopathologic entity. Chest 2004; 126: 2007-2013.

2 Travis WD, Costabel U, Hansell DM, et al. An official American Thoracic Society/European Respiratory Society statement: update of the international multidisciplinary classification of the idiopathic interstitial pneumonias. $A m$ J Respir Crit Care Med 2013; 188: 733-748.

3 Azoulay E, Paugam B, Heymann MF, et al. Familial extensive idiopathic bilateral pleural fibrosis. Eur Respir J 1999; 14: 971-973.

4 von der Thüsen JH, Hansell DM, Tominaga M, et al. Pleuroparenchymal fibroelastosis in patients with pulmonary disease secondary to bone marrow transplantation. Mod Pathol 2011; 24: 1633-1639.

5 Hirota T, Fujita M, Matsumoto T, et al. Pleuroparenchymal fibroelastosis as a manifestation of chronic lung rejection? Eur Respir J 2012; 41: 243-245.

6 Reddy TL, Tominaga M, Hansell DM, et al. Pleuroparenchymal fibroelastosis: a spectrum of histopathological and imaging phenotypes. Eur Respir J 2012; 40: 377-385.

7 Alvarado CS, Boat TF, Newman AJ. Late-onset pulmonary fibrosis and chest deformity in two children treated with cyclophosphamide. J Pediatr 1978; 92: 443-446.

8 Harada T, Yoshida Y, Kitasato Y, et al. The thoracic cage becomes flattened in the progression of pleuroparenchymal fibroelastosis. Eur Respir Rev 2014; 23: 263-266.

9 Malik SW, Myers JL, DeRemee RA, et al. Lung toxicity associated with cyclophosphamide use. Two distinct patterns. Am J Respir Crit Care Med 1996; 154: 1851-1856.

10 Becker CD, Gil J, Padilla ML. Idiopathic pleuroparenchymal fibroelastosis: an unrecognized or misdiagnosed entity? Mod Pathol 2008; 21: 784-787.

11 Taylor PM, O'Driscoll BR, Gattamaneni HR, et al. Chronic lung fibrosis following carmustine (BCNU) chemotherapy: radiological features. Clin Radiol 1991; 44: 299-301.

12 O'Driscoll BR, Hasleton PS, Taylor PM, et al. Active lung fibrosis up to 17 years after chemotherapy with carmustine (BCNU) in childhood. N Engl J Med 1990; 323: 378-382.

13 Parish JM, Muhm JR, Leslie KO. Upper lobe pulmonary fibrosis associated with high-dose chemotherapy containing BCNU for bone marrow transplantation. Mayo Clin Proc 2003; 78: 630-634.

\section{The effect of roflumilast in addition to LABA/LAMA/ICS treatment in COPD patients}

\author{
To the Editor:
}

Recently, roflumilast has been added as a therapeutic option for chronic obstructive pulmonary disease (COPD). Roflumilast is a selective phosphodiesterase type 4 (PDE4) inhibitor [1]. The main concern of the large-scale studies performed was that they did not assess the effect of roflumilast in addition to a combination product such as long-acting $\beta_{2}$-agonists (LABA) or long-acting muscarinic agents (LAMA) combined with inhaled corticosteroids (ICS) [2]. A novel technology called functional respiratory imaging (FRI) defines, in great detail, lung geometry and regional changes in airway volume and resistance [3-5]. By assessing changes close to the site of action of the intervention, the method is more sensitive (higher effect size) compared with standard pulmonary function tests (PFT) [3]. This implies that the mode of action of an intervention can be assessed in a small number of patients, while maintaining sufficient power to have statistically significant results $[3,4]$. We performed a study aimed at investigating the mode of action of roflumilast in COPD patients on top of triple therapy (LABA/LAMA/ICS), using PFT, exercise tolerance tests, patient-reported outcomes (PRO) and FRI. The hypothesis was that roflumilast provides a large benefit to a subset of COPD patients and that FRI can assist in phenotyping these responders. Ideally, a PFT parameter could be defined that could identify the responding phenotype.

A total of 41 COPD patients were included from January 2012 until October 2012 in two clinical centres. Patients were block randomised with a ratio of three treated to one placebo control subject, to eliminate any seasonal influences. In total, 30 patients were treated with roflumilast and 11 patients received placebo. The 
study consisted of two visits, one at baseline and one after 6 months of treatment with either roflumilast (500- $\mu$ g tablet, once daily) or a placebo. During these two visits, the following tests were performed postbronchodilation: spirometry, body plethysmography, 6-min walk test (6MWT), PRO and FRI.

The FRI parameters were derived from low-dose computed tomography scans at total lung capacity (TLC) and functional residual capacity (FRC). Segmentation principles allowed quantification and visualisation of the lung, lobar and airway volumes. Computational fluid dynamics was used to determine the airway resistance. FRI outcome parameters included: image-based lobar volume at FRC (iLobes_FRC), imagebased airway volume at TLC (iVaw) and image-based airway resistance at TLC (iRaw). More details and validation of FRI can be found in DE BACKER et al. [5]. The study was approved by the ethical commissions of all participating centres. All patients signed an informed consent (NCT01480661).

The baseline mean $\pm \mathrm{SD}$ forced expiratory volume in $1 \mathrm{~s}$ (FEV1) was $41.3 \pm 12.17 \%$ predicted in the roflumilast group and $47.28 \pm 11.19 \%$ predicted in the placebo control group. A significant improvement in FEV1 was observed in the roflumilast group compared to baseline (mean \pm SD increase of $66 \pm 120 \mathrm{~mL}$; $\mathrm{p}=0.01)$ and compared to placebo $(\mathrm{p}=0.006)$. In the placebo group, the FEV1 declined by $59 \pm 71 \mathrm{~mL}$, which was borderline significant compared to baseline $(\mathrm{p}=0.052)$. When considering the entire population, no significant improvement in 6MWT was observed in the treated group.

In the roflumilast treatment arm, eight (35\%) patients exhibited an FEV1 improvement by more than the measurement accuracy of FEV1, which was recently determined to be $120 \mathrm{~mL}$ [6]. In this group of responders, the mean $\pm \mathrm{SD}$ increase in $\mathrm{FEV} 1$ was $186.25 \pm 6.76 \mathrm{~mL}$. In order to gain insight into the phenotype of the responders, other parameters were assessed where the responders differed from the other patients. When assessing the results of the exercise tolerance test, responders were considered to be patients who felt significantly (Borg fatigue score $\mathrm{p}=0.013$ ) worse after the 6MWT performed at baseline compared to the nonresponders. The mean $\pm \mathrm{SD}$ Borg fatigue score after the $6 \mathrm{MWT}$ at baseline was $5.60 \pm 1.52$ for patients with an improvement in FEV $1>120 \mathrm{~mL}$. The Borg fatigue score for the other patients after $6 \mathrm{MWT}$

a) iVaw changes $\%$

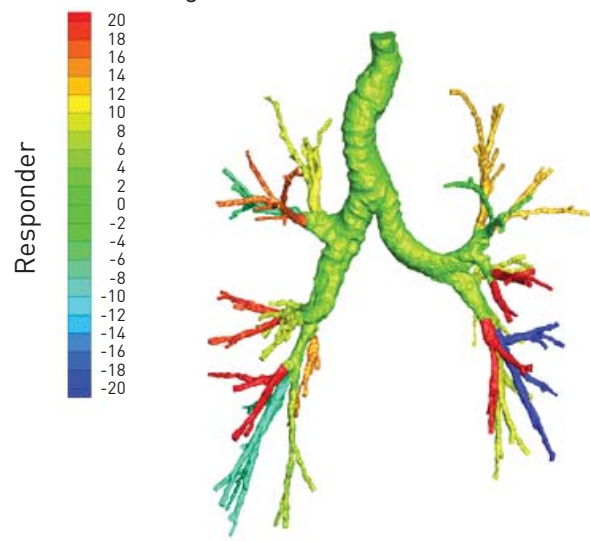

c) iVaw changes $\%$

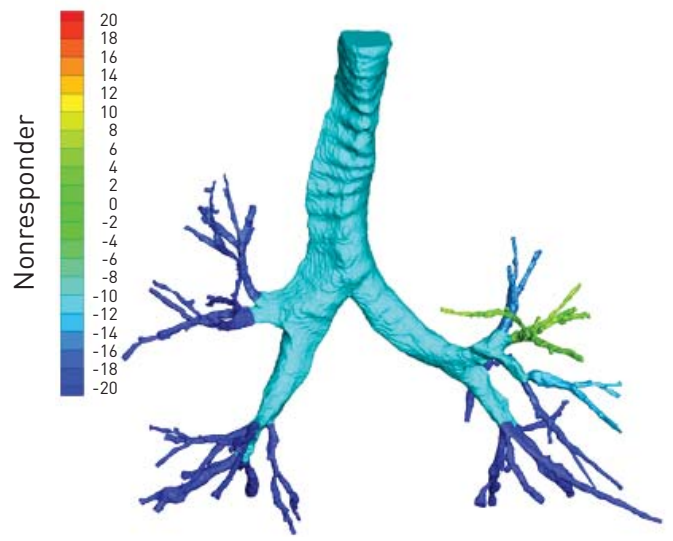

b) iRaw changes \%

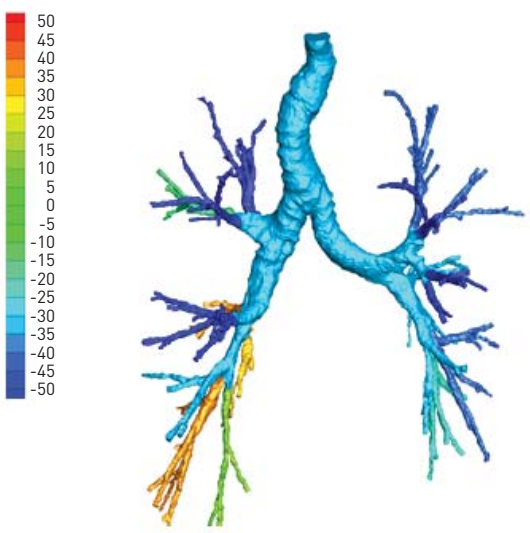

d) iRaw changes \%

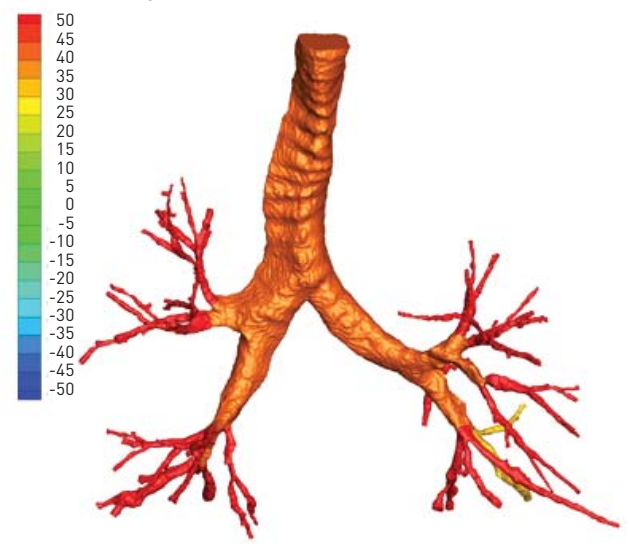

FIGURE 1 Change in a, c) image-based airway volume (iVaw) and b, d) image-based airway resistance (iRaw), for a, b) a patient responding to treatment and $c, d$ ) a patient not responding to treatment with roflumilast. 
at baseline was $2.41 \pm 2.29$. When assessing the hyperinflation in terms of lobar volumes, it could be observed that the iLobes_FRC in the responders was reduced significantly (mean $\pm \mathrm{SD}$ decrease of $1.98 \pm 9.88 \% ; \mathrm{p}=0.023$ ) after 6 months of treatment with roflumilast compared to the other patients in the group, whose iLobes_FRC increased by $3.09 \pm 10.12 \%$. The iLobes_FRC in the placebo group increased by $7.11 \pm 13.80 \%$, which was significantly different from the responders $(p=0.003)$ but not significantly different from the other treated patients $(p=0.16)$. The responders improved in terms of the $6 \mathrm{MWT}$ by mean \pm SD $48.5 \pm 38.0 \mathrm{~m}$, which was significantly different from the other treated patients $(\mathrm{p}=0.039)$, who only improved by $6.54 \pm 46.54 \mathrm{~m}$, and from the placebo group $(\mathrm{p}=0.012)$, who performed worse after 6 months $(6 \mathrm{MWT}$ decreased by $27.63 \pm 41.76 \mathrm{~m})$. There was significantly $(\mathrm{p}<0.0001)$ more bronchodilation in terms of $\mathrm{i} V$ aw in the responders compared to the other patients. The $\mathrm{i} V$ aw in the responders increased by mean \pm SD $19.50 \pm 38.58 \%$, while the in the other patients, the $i V_{\text {aw }}$ was reduced by $11.53 \pm 8.46 \%$. At the same time, the $\mathrm{i}$ Raw improved in the responder group (mean \pm SD decrease of $24.31 \pm 28.52 \%$ ), which was significantly different $(\mathrm{p}<0.0001)$ from the other patients, whose iRaw increased by $66.18 \pm 73.52 \%$ (fig. 1).

The current study confirmed the potential of PDE4 inhibitors to improve lung function in COPD patients even when administered in addition to triple (LABA/LAMA/ICS) therapy, which has never been previously studied. At the same time, the FRI outcome parameters were able to provide a hypothesis for the mode of action of roflumilast leading to the improvements observed in the lung function. It appears that the patients who are doing well when using this PDE4 inhibitor are the patients who are prone to dynamic hyperinflation, as indicated by the PRO after the 6MWT. Apparently, treating these patients with roflumilast reduced inflammation in the smaller airways, resulting in an improvement in the regional (lobar) hyperinflation as measured by FRI. Given that the product was administered orally, we could speculate that the effective site of action was different compared to the site of action of the standard of care inhalation therapy. It therefore appears that the significant improvement in FEV1 in the responder group is not a direct result of the PDE4 inhibitor but due to an enhanced efficacy of the triple therapy caused by more effective deposition. Potentially, the exercise tolerance tests in combination with PRO could be used at baseline to screen for responders. The relative ease and low cost of these tests facilitates the practical implementation. The findings of this initial proof-of-concept study need to be confirmed in a larger prospective trial. airflow distribution http://ow.ly/v6S0O

Wilfried De Backer ${ }^{1}$, Wim Vos $^{2}$, Cedric Van Holsbeke ${ }^{2}$, Samir Vinchurkar ${ }^{2}$, Rita Claes ${ }^{1}$, Annemie Hufkens ${ }^{1}$, Paul M. Parizel ${ }^{3}$, Lieven Bedert ${ }^{4}$ and Jan De Backer ${ }^{2}$

${ }^{1}$ Dept of Respiratory Medicine, University Hospital Antwerp, Antwerp, Belgium. ${ }^{2}$ Fluidda nv, Kontich, Belgium. ${ }^{3}$ Dept of Radiology, University Hospital Antwerp, Antwerp, Belgium. ${ }^{4}$ Dept of Respiratory Medicine, ZNA Middelheim Hospital, Antwerp, Belgium.

Correspondence: Jan De Backer, Groeningenlei 132, 2550 Kontich, Belgium. E-mail: Jan.DeBacker@Fluidda.com

Received: Jan 152014 | Accepted after revision: March 122014 | First published online: May 22014

Support statement: This study was funded by Takeda (Zurich, Switzerland).

Conflict of interest: Disclosures can be found alongside the online version of this article at erj.ersjournals.com

\section{References}

1 Chong J, Poole P, Leung B, et al. Phosphodiesterase 4 inhibitors for chronic obstructive pulmonary disease. Cochrane Database Syst Rev 2011; 5: CD002309.

2 European Medicines Agency. Daxas: roflumilast. European Public Assessment Report - summary for the public. EMA/268074/2010. Date first published: July 28, 2010. Date last updated: April 17, 2013.

3 De Backer LA, Vos W, De Backer J, et al. The acute effect of budesonide/formoterol in COPD: a multi-slice computed tomography and lung function study. Eur Respir J 2012; 40: 298-305.

4 Vos W, De Backer J, Poli G, et al. Novel functional imaging of changes in small airways of patients treated with extrafine beclomethasone/formoterol. Respiration 2013; 86: 393-401.

5 De Backer JW, Vos WG, Vinchurkar SC, et al. Validation of computational fluid dynamics in CT-based airway models with SPECT/CT. Radiology 2010; 257: 854-862.

6 Janssens W, Liu Y, Liu D, et al. Quality and reproducibility of spirometry in COPD patients in a randomized trial (UPLIFTß). Respir Med 2013; 107: 1409-1416. 